See Article page 1619.

\section{Commentary: Comparing sleeve lobectomy with pneumonectomy for central lung cancer: $A$ randomized study will never be conducted}

\author{
Michael Lanuti, MD
}

Central tumors in the lung challenge our specialty on a daily basis, and strategies to avoid pneumonectomy are far more common now compared with 20 years ago, when retrospective series introduced the concept that sleeve lobectomy could yield equivalent long-term survival with reduced morbidity and mortality. In contrast to some studies and perhaps counterintuitive, locoregional failures were worse with pneumonectomy (35\%) compared with sleeve lobectomy $(22 \%)$ in an unmatched analysis by Deslauriers and colleagues. ${ }^{1}$ Overall, any retrospective comparison of outcomes in patients selected for pneumonectomy or sleeve lobectomy is rather difficult to analyze by virtue of a strong selection bias (which takes into account pulmonary reserve, tumor burden, and the desire to achieve R0 resection) and the technical prowess of the surgeon. Sleeve lobectomy is far more technically challenging than pneumonectomy and frequently performed only in high-volume centers. An attempt to propensity match patients $(n=794$ per group) from a French nationwide database ${ }^{2}$ demonstrated no difference in the postoperative mortality comparing pneumonectomy with sleeve lobectomy; however, early overall and disease-free survival favored sleeve lobectomy. In a propensity-matched study derived from the US National Cancer Database ( $\mathrm{n} \sim 1500$ patients per group), sleeve resections were associated with an overall survival

\footnotetext{
From the Division of Thoracic Surgery, Massachusetts General Hospital, Boston, Mass.

Disclosures: The author reported no conflicts of interest.

The Journal policy requires editors and reviewers to disclose conflicts of interest and to decline handling or reviewing manuscripts for which they may have a conflict of interest. The editors and reviewers of this article have no conflicts of interest.

Received for publication Oct 4, 2020; revisions received Oct 4, 2020; accepted for publication Oct 6, 2020; available ahead of print Oct 13, 2020.

Address for reprints: Michael Lanuti, MD, 55 Fruit St, Founders 7, Boston, MA 02114 (E-mail: mlanuti@mgh.harvard.edu).

J Thorac Cardiovasc Surg 2021;162:1629-30

$0022-5223 / \$ 36.00$

Copyright (C) 2020 by The American Association for Thoracic Surgery

https://doi.org/10.1016/j.jtcvs.2020.10.014
}

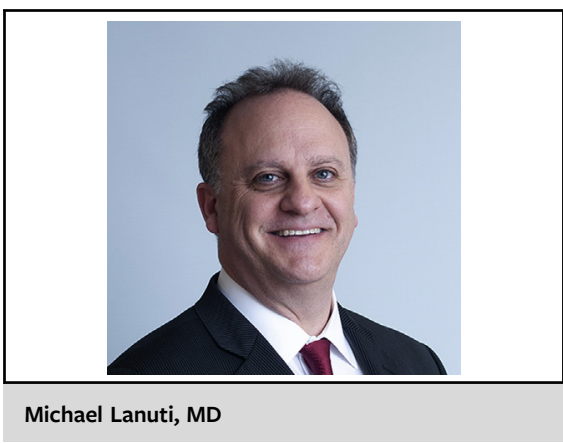

CENTRAL MESSAGE

Since a randomized trial

comparing disease-specific sur-

vival of sleeve lobectomy with

pneumonectomy will never be

conducted, an approximation of

benefit can only be achieved with

large matched cohorts.

advantage compared with pneumonectomy; however, the benefit was only evident in the first 12 months after the operation. $^{3}$ As systemic therapies for locally advanced resectable non-small cell lung cancer improve, parenchymal-sparing techniques for central tumors have become even more attractive, particularly with the addition and implementation of induction check point inhibitors. ${ }^{4}$

In this edition of the Journal, ${ }^{5}$ the authors perform a retrospective review of a large number of patients $(\mathrm{n}=1981)$ undergoing sleeve lobectomy or pneumonectomy over a 15 -year period derived from a single very high-volume institution. The primary end points were 30and 90-day mortality, postoperative complications, and survival. Sleeve lobectomy was performed in about one half the patients, with double sleeve (arterioplasty) in $10 \%$. All resections were R0. As would be expected, the pneumonectomy group had larger tumors, more advanced stage, and were younger. The groups were propensity matched $(n=665$ each group $)$ where 90-day mortality appeared better in the sleeve resection group with fewer complications. Acute respiratory distress syndrome and bronchopleural fistula were greater in the pneumonectomy group despite matching. Sleeve had improved 5-year overall $61 \%$ versus $44 \%$ compared with pneumonectomy in the matched analysis. Interestingly, the incidence of recurrence was greater for pneumonectomy in all stages and was most significant 
for stage IIIA disease. Furthermore, locoregional recurrence was not different between groups, but distant recurrence was significantly greater for the pneumonectomy patients invoking the more advanced stage in this group. It is not entirely clear if neoadjuvant or adjuvant therapy was employed in these patients and if there was any impact on survival.

This study represents the largest single-center study comparing outcomes for sleeve lobectomy and pneumonectomy. One should take note that recurrence was greater for pneumonectomy in all stages and was most significant for stage III disease. The distinction of worse overall and disease-free survival of pneumonectomy $(n=250)$ versus sleeve lobectomy $(n=256)$ for $\mathrm{N} 2$ disease is a novel finding and is rather striking on the Kaplan-Meier curves in the supplementary data. This observation may be a metric that surgeons can use when considering pneumonectomy for resectable $\mathrm{N} 2$ disease where clearance of all original central lymphatic disease may become less important with improving systemic therapies.

\section{References}

1. Deslauriers J, Gregoire J, Jacques LF, Piraux M, Guojin L, Lacasse Y. Sleeve lobectomy versus pneumonectomy for lung cancer: a comparative analysis and sites of recurrence. Ann Thorac Surg. 2005:79:1467.

2. Pagès PB, Mordant P, Renaud S, Brouchet L, Thomas PA, Dahan M, et al. Sleeve lobectomy may provide better outcomes than pneumonectomy for NSCLC. A decade in a nationwide study. J Thorac Cardiovasc Surg. 2017; 153:184-95.

3. Abdelsattar ZM, Shen RK, Yendamuri S, Cassivi S, Nichols FC, Wigle DA, et al. Outcomes after sleeve lung resections versus pneumonectomy in the United States. Ann Thorac Surg. 2017;104:1656-64.

4. Forde PM, Chaft JE, Smith KN, Anagnostou V, Cottrell TR, Hellmann MD, et al Neoadjuvant PD-1 blockade in resectable lung cancer. N Engl J Med. 2018;378 1976-86.

5. Chen J, Soultanis KM, Sun F, Gonzalez-Rivas D, Duan L, Wu L, et al. Outcomes of sleeve lobectomy versus pneumonectomy: a propensity score-matched study. $J$ Thorac Cardiovasc Surg. 2021;162:1619-28.e4.
See Article page 1619.

\section{Commentary: To sleeve or not to sleeve: Still a question?}

Kenneth P. Seastedt, MD, ${ }^{a}$ and

Chuong D. Hoang, $\mathrm{MD}^{\mathrm{b}}$

Despite sleeve resections being performed since the 1940s as an alternative to pneumonectomy for lung cancers, the benefits of this technique continued to be debated. ${ }^{1}$ Chen and colleagues, ${ }^{2}$ in this issue of the Journal, retrospectively summarize their experience of patients who underwent pneumonectomy versus bronchial sleeve resection (with or without vascular sleeve or arterioplasty) for centrally

From the a Department of Surgery, Uniformed Services University of the Health Sciences F. Edward Hébert School of Medicine; and ${ }^{\mathrm{b}}$ Thoracic Surgery Branch, National Cancer Institute-National Institutes of Health, Center for Cancer Research, and The Clinical Center, Bethesda, Md.

Disclosures: The authors reported no conflicts of interest.

The Journal policy requires editors and reviewers to disclose conflicts of interest and to decline handling or reviewing manuscripts for which they may have a conflict of interest. The editors and reviewers of this article have no conflicts of interest.

Received for publication Aug 30, 2020; revisions received Aug 30, 2020; accepted for publication Aug 31, 2020; available ahead of print Sept 3, 2020.

Address for reprints: Chuong D. Hoang, MD, 10 Center Dr, Mail Code 1201, Room 43940, Bethesda, MD 20892 (E-mail: chuong.hoang@nih.gov).

J Thorac Cardiovasc Surg 2021;162:1630-1

0022-5223/\$0.00

Published by Elsevier Inc. on behalf of The American Association for Thoracic Surgery

https://doi.org/10.1016/j.jtcvs.2020.08.100
Check for updates

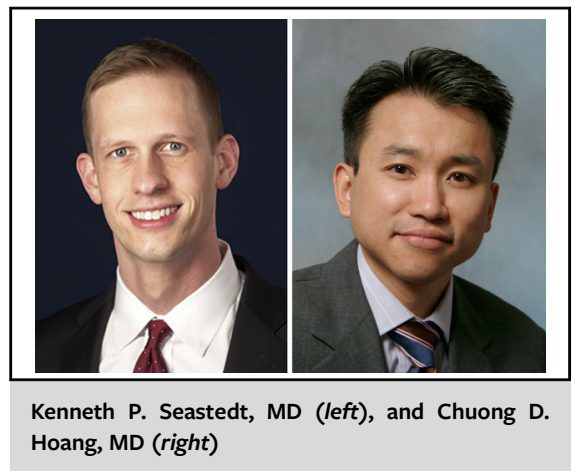

CENTRAL MESSAGE

Analysis of a large, single-

institution series of sleeve

resection versus pneumonec-

tomy for central lung cancer

supports the preference of a

lung-sparing technique when-

ever the anatomy is permissible.

located tumors. It represents among the largest series and attempts to improve the ongoing discussion regarding the benefits of sleeve resection. ${ }^{3}$ Certainly, their results will serve as a benchmark for future clinical comparisons.

In total, 1981 patients met inclusion criteria and were propensity score-matched to groups of 665 patients in each 